\title{
Evaluation of aphrodisiac activity of ethanol extract of Ganoderma lucidum in male Wistar rats
}

\author{
Hammad Ahmed ${ }^{1}$ and Muhammad Aslam ${ }^{1,2^{*}}$ (D)
}

\begin{abstract}
Background: Ganoderma lucidum was traditionally used to manage male sexual dysfunction. This study was designed to investigate and establish the traditional aphrodisiac potential of the herb.

Methods: Aphrodisiac potential was evaluated following the oral administration of two different doses (150 and $300 \mathrm{mg} / \mathrm{kg}$ ) of ethanol extract of Ganoderma lucidum. Sildenafil citrate (Viagra) and distilled water were used as positive and negative controls respectively. Mounting, intromission and ejaculation frequencies, mating performance, and orientation activities towards females, towards the environment, and towards self were observed. Serum testosterone levels were also evaluated.

Results: The results of the study show that the extract has significantly increased the mounting behavior and mating performance of the rats. There was also significant increase in the number of intromissions and ejaculations. The rats treated with extract were more interested in female rats as indicated by significant increase in the number of anogenital sniffing and climbing. Serum testosterone levels were also significantly increased in the treatment groups.

Conclusion: Ethanol extract of Ganoderma lucidum possesses aphrodisiac activity in male Wistar rats. The lower dose of $150 \mathrm{mg} / \mathrm{kg}$ was more effective in terms of aphrodisiac potential of the extract.
\end{abstract}

Keywords: Ganoderma lucidum, Sildenafil citrate, Aphrodisiac, Testosterone

\section{Background}

Male infertility is due to any problem in the male reproductive system, including: decreased sexual desire, barrenness, premature ejaculation and erectile dysfunction [1]. Sex is a highly important aspect of living organisms which plays a key role in their survival. Substances that increase the sexual desire are called aphrodisiac agents. The term aphrodisiac is derived from "Aphrodite", that means the "Greek goddess of sexuality and love" [2]. In allopathic medicine, there are various drugs which can increase the sexual craving in both male and female, although these drugs have numerous harmful effects [3]. Phosphodiesterase type 5 inhibitors, like tadalafil (Cialis) and sildenafil (Viagra) are the most commonly used

\footnotetext{
* Correspondence: Pharmacologist1@yahoo.com

${ }^{1}$ Department of Pharmacology, Faculty of Pharmacy, Ziauddin University, Karachi 75600, Pakistan

${ }^{2}$ Department of Pharmacology, Faculty of Pharmacy, University of Sindh, Jamshoro 76080, Pakistan
}

aphrodisiac agents, but these drugs cause dizziness, headache, visual disturbance, pulse irregularities, dyspepsia, priapism, diarrhoea and flushing [4].

Mushrooms have been one of the major sources of several medicinal products. There are around 10,000 varieties of mushrooms, out of which 2000 have nonpoisonous effects and around 300 of them have shown important medicinal effects [5]. Studies show that mushroom extracts are advantageous for the human body, as they have shown several pharmacological activities such as anti-bacterial, anti-inflammatory, anti-viral and anti-hyperglycemic activity [6].

Ganoderma lucidum (reishi) is denoted as a sacred mushroom in Chinese culture [7]. These days, reishi has gained a great value in medicinal product development because of its medicinal properties [8]. Ganoderma luci$d u m$ is not only used to treat common health problems, 
[9] but it has also been used as an anti-cancer agent alone or with western chemotherapy medications [10].

From the fruiting bodies, spores, and mycelia of reishi, various types of bioactive compounds have been identified which commonly consist of proteins, peptides, triterpenoids, sterols, polysaccharides, steroids, nucleotides and trace elements [11, 12]. Ganoderma lucidum has shown various pharmacological activities which include antiviral (anti-HIV), hepatoprotective, anti-ulcer antibacterial, anti-tumour, anti-inflammatory, radio-protective, age promoting, analgesic, hypolipidemic, sleep promoting, cytotoxic, chemopreventive, antifibrotic, antiatherosclerotic, antidiabetic, radical scavenging and antioxidative properties $[8,11,13-16]$. In this study, we have evaluated the potential aphrodisiac activity of ethanol extract of Ganoderma lucidum (GLE) in male Wistar rats.

\section{Methods}

\section{Drugs and chemicals}

Ganoderma lucidum extract composed of cracked spores and fruiting bodies, branded ReishiMaxGLPTM, was procured from Pharmanex Inc. (United States of America). Sildenafil was purchased from Pfizer, USA, while progesterone and estradiol benzoate were procured from Sigma Aldrich, Pakistan.

\section{Animals}

Healthy adult rats (Wistar strain) bearing weight of 150-200 g were purchased from the animal house of Dow University of Health Sciences, Pakistan. Polypropylene cages have been used for keeping the animals under controlled conditions at room temperature $\left(25-30{ }^{\circ} \mathrm{C}\right)$ with light-dark cycle of $12 \backslash 12 \mathrm{~h}$. Standard diet and water ad libitum were given to the rats. Handling of the animals was done according to the requirements mentioned in "Guidelines for the care and use of laboratory animals $8^{\text {th }}$ edition" [17]. Prior approval of the ethical review committee of Ziauddin University was taken before starting this research study.

\section{Animal groups}

Male rats were divided into four groups $(n=6)$ :

Group I: Control group, given distilled water $(10 \mathrm{ml} / \mathrm{kg})$ orally for 40 days.

Group II: Treatment group, given extract $(150 \mathrm{mg} / \mathrm{kg})$ for 40 days.

Group III: Treatment group, given extract (300 mg/kg) for 40 days.

Group IV: Standard drug group, given sildenafil citrate $(5 \mathrm{mg} / \mathrm{kg})$ for 40 days.

\section{Preparation of male rats}

Sexual behaviour training was given to male rats for 10 days. The animal that did not show any sexual interest was replaced by another sexually active rat $[18,19]$.

\section{Preparation of female rats}

Oestrus (heat) was developed artificially in female rats by giving progesterone $(0.5 \mathrm{mg} / 100 \mathrm{~g}$ body weight $)$ and estradiol benzoate (10 microgram/100 g body weight) over the subcutaneous route sequentially before mating. Before conducting the experiment the receptivity of female rats was ensured $[18,19]$.

A number of parameters such as mounting behaviour, mating performance, orientation activities of male rats towards the surrounding, towards female and towards themselves were observed for the assessment of aphrodisiac activity of the extract.

\section{Mounting behaviour test}

The climbing property of male rats onto the female rats is known as "Mounting". To assess the number of mounts, the mounting behaviour test was performed. Males, treated with the extract, were paired with non-oestrus female rats. The behaviour of the animals was noted for $3 \mathrm{~h}$ on the 10th, 20th and 40th day of the study. Male rats were placed individually in each cage. After 15 min of acclimation, non-oestrus female was introduced into each cage and number of mounts were noted at the beginning of 1 st hour for next $15 \mathrm{~min}$. Every female was then given a resting period of $105 \mathrm{~min}$ by pulling it from each cage. The females were again introduced into the cages and the number of mounts were again noted for $15 \mathrm{~min}$ before the end of 3rd hour of the test. The test was performed at room temperature of 25-27 ${ }^{\circ} \mathrm{C}$ between 9 a.m. to 12 p.m. $[18,19]$.

\section{Determination of mating performance}

In this test every male rat was settled separately in a glass cage. After the acclimation period of $15 \mathrm{~min}$, five oestrus females were admitted into each cage and they cohabited overnight. For the detection of any sperms in females, microscopic investigation of the vaginal smear of every female rat was performed. Sperm positive females were noted in every group $[18,19]$.

\section{Test for libido}

In this test sexually experienced male rats demonstrating vigorous sexual performance were selected. Mounting Frequency (MF) was observed in these rats in the evening of 10th, 20th and 40th day. Before initiating the observation, the sheath of the penis was retracted to expose the penis of rats and xylocaine 5\% ointment (AstraZeneca Pharma) was applied at the interval of 5, 15 and $30 \mathrm{~min}$. Each male rat was allocated separately in 


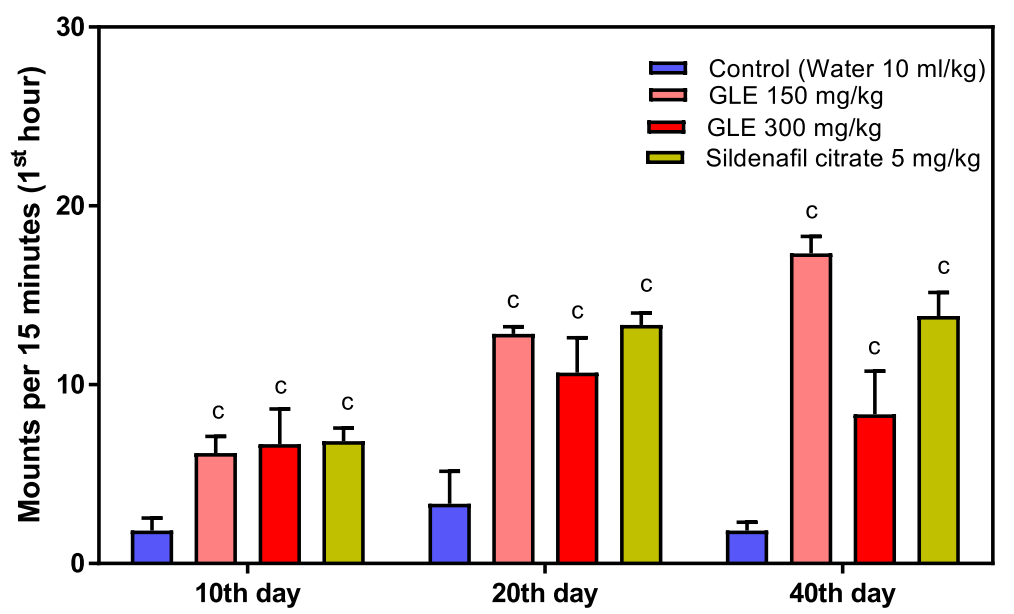

Fig. 1 Effect of Ganoderma lucidum on mounting behavior (1st hour) in male rats. Animals per group $(n)=6$. The values are mean \pm S.E.M.; ${ }^{a} p<0.05$; ${ }^{b} p<0.01 ;{ }^{c} p<0.001$ when compared with control group. (One-way ANOVA followed by Tukey's post hoc test)

a cage and female rats were admitted in the similar cage. The total number of intromissions and ejaculations were observed [20].

\section{Determination of the orientation activities of male rats}

In this test the behavioural activities of the male rats, towards the surrounding, towards themselves and towards females were examined. The rats were observed and the number of climbings, genital groomings, lickings and anogenital sniffings were counted for one hour [21].

\section{Preparation of serum for testosterone analysis}

The blood was collected via cardiac puncture using chloroform anaesthesia. Using sterilized syringe, $5 \mathrm{ml}$ of blood was collected in appropriately labelled blank tubes containing no anti-coagulant. The tubes were given 5 to $10 \mathrm{~min}$ for coagulation before they were subjected to centrifugation. The needles were changed for every single animal. After coagulation these tubes were centrifuged at $3000 \mathrm{rpm}$ for $10 \mathrm{~min}$. The supernatant formed after centrifugation was sucked and collected in a clean, empty tube for testosterone assay [22].

\section{Testosterone analysis}

Quantitative determination of total testosterone was done by the competitive imunoenzymatic colorimetric method mentioned in the manufacturer's test procedure (Diametra testosterone ELISA kit). The absorbance was noted at $420 \mathrm{~nm}$ against a reference wavelength of $620-630 \mathrm{~nm}$.

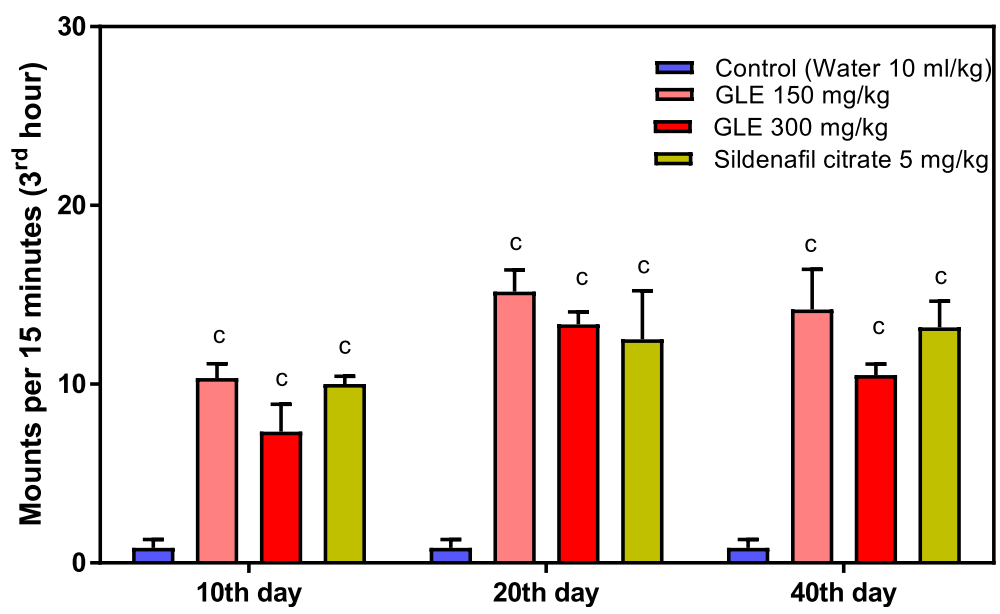

Fig. 2 Effect of Ganoderma lucidum on mounting behavior (3rd hour) in male rats. Animals per group $(\mathrm{n})=6$. The values are mean \pm S.E.M.; ${ }^{\mathrm{a}} p<0.05$; ${ }^{b} p<0.01 ;{ }^{c} p<0.001$ when compared with control group. (One-way ANOVA followed by Tukey's post hoc test) 


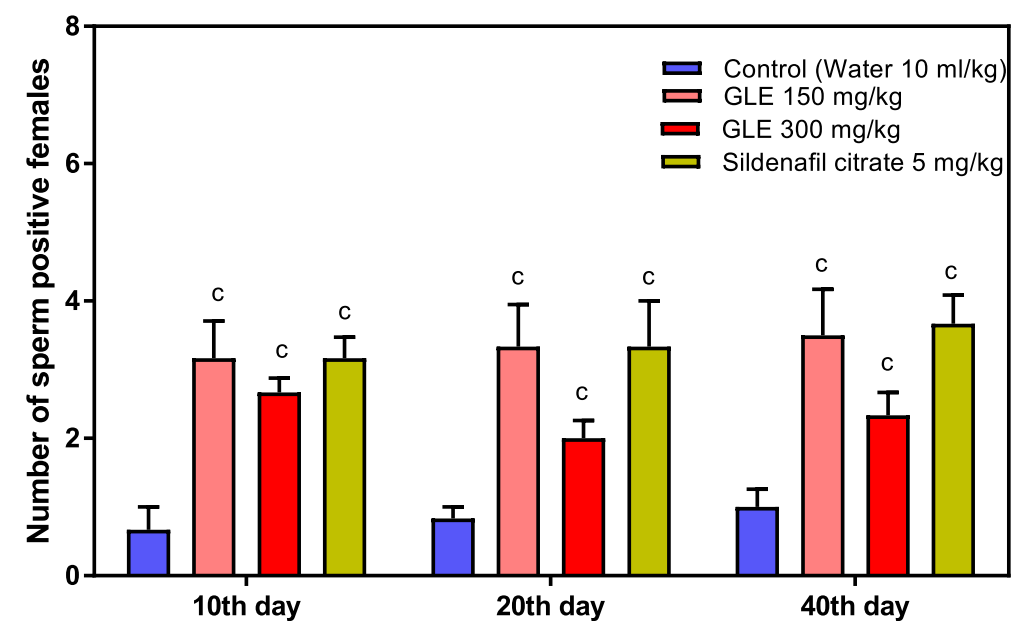

Fig. 3 Effect of Ganoderma lucidum on mating performance test in male rats. Animals per group $(n)=6$. The values are mean \pm S.E.M.i ${ }^{a} p<0.05$; ${ }^{b} p<0.01 ;{ }^{c} p<0.001$ when compared with control group. (One-way ANOVA followed by Tukey's post hoc test)

\section{Statistical analysis}

One-way ANOVA followed by Tukey's test was used for analysing the data. Data were expressed as mean \pm standard error of mean. A statistical level of 0.05 or less was accepted as significant.

\section{Results}

In mounting behavior test, during 1st and 3rd hour of the test, GLE showed extremely significant effect at both doses viz. $150 \mathrm{mg} / \mathrm{kg}$ and $300 \mathrm{mg} / \mathrm{kg}$ when compared with control group. However, $150 \mathrm{mg} / \mathrm{kg}$ GLE was noted as the most effective aphrodisiac dose (Figs. 1 and 2).

An extremely significant difference was recorded in mating performance test. The results show that there were more sperm positive females in GLE $(150 \mathrm{mg} / \mathrm{kg}$ and $300 \mathrm{mg} / \mathrm{kg}$ ) groups in comparison to normal control group on 10th, 20th and 40th day of the study. Our results suggest that $150 \mathrm{mg} / \mathrm{kg}$ dose is more effective than $300 \mathrm{mg} / \mathrm{kg}$ dose in terms of mating performance test. The results of $150 \mathrm{mg} / \mathrm{kg}$ are comparable to sildenafil citrate, positive control (Fig. 3).

The results of libido test show that the number of intromissions and ejaculations in GLE groups was significantly high when compared with control group. We observed very promising results of GLE in terms of the number of intromissions and ejaculations. The effect of GLE $(150 \mathrm{mg} / \mathrm{kg})$ was greater than sildenafil citrate in libido test (Figs. 4 and 5).

The results of orientation activities show significant increase in the activities of male rats in terms of anogenital sniffing, licking, climbing and genital grooming. There was extremely significant increase in the orientation

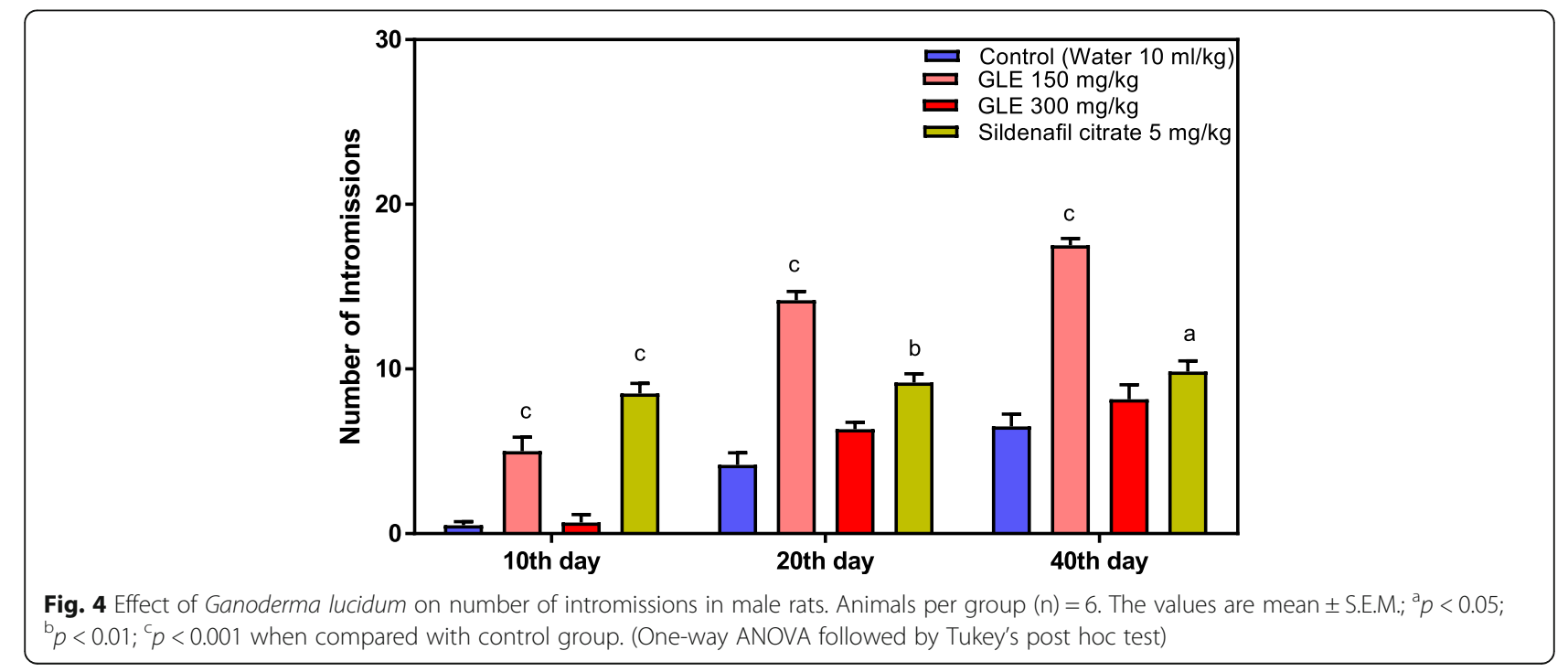




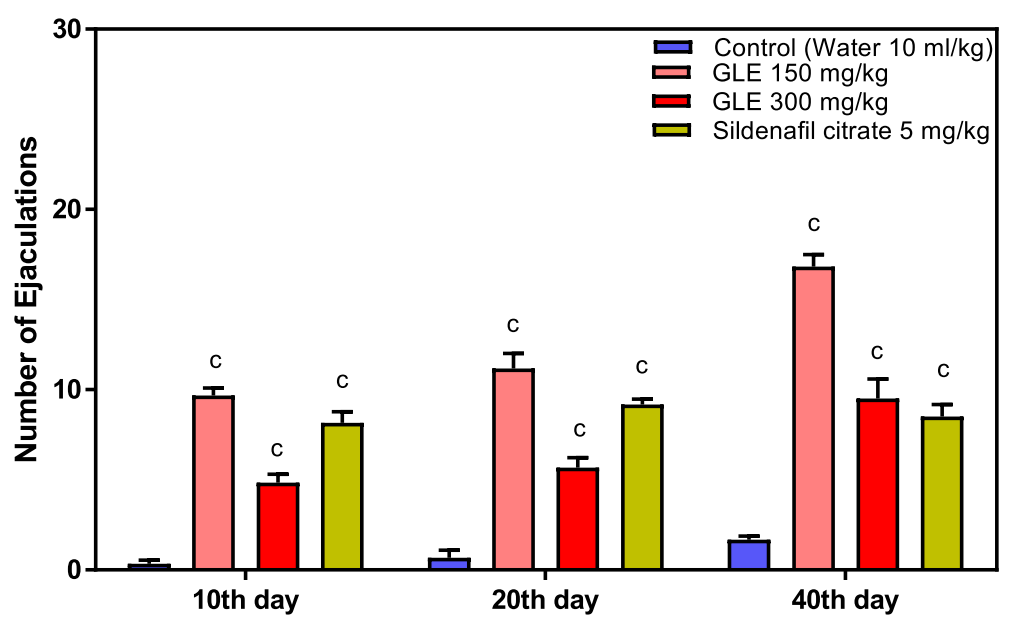

Fig. 5 Effect of Ganoderma lucidum on number of ejaculations in male rats. Animals per group $(n)=6$. The values are mean \pm S.E.M.; ${ }^{a} p<0.05$; ${ }^{b} p<0.01$; ${ }^{c} p<0.001$ when compared with control group. (One-way ANOVA followed by Tukey's post hoc test)

activities of GLE (150 mg/kg) when compared with control group (Figs. 6, 7, 8 and 9).

Ganoderma lucidum significantly increased the serum testosterone levels in male rats when compared with control group (Fig. 10).

\section{Discussion}

Mounting and intromission frequencies are the important indicators of libido. Mounting frequency shows the increase in sexual desire and increase in intromission frequency reflects the ability of penile erection, penile introduction, and the responses which trigger ejaculation [23, 24].

In this study, the results show that Ganoderma lucidum increases the number of mounts which represents that continuous administration of the extract significantly increases the sexual desire when compared with control group and sildenafil citrate $5 \mathrm{mg} / \mathrm{kg}$ group.

The ability of doing sex is not only dependent on sexual desire but it also depends on erectile function. If an individual is suffering from erectile dysfunction, it can cause a major barrier in sexual performance even in presence of strong sexual desire. Sexual performance depends on neurovascular occasions by means of hemodynamic mechanism of penile erection [25]. Therefore, the increase in the intromission and ejaculation frequencies with the administration of GLE indicates that extract significantly increases the sexual performance of male rats. The increase in the intromission frequency proposed that adequate penile erection was accomplished by this extract [26]. Hence, GLE may be investigated for the treatment of erectile dysfunction.

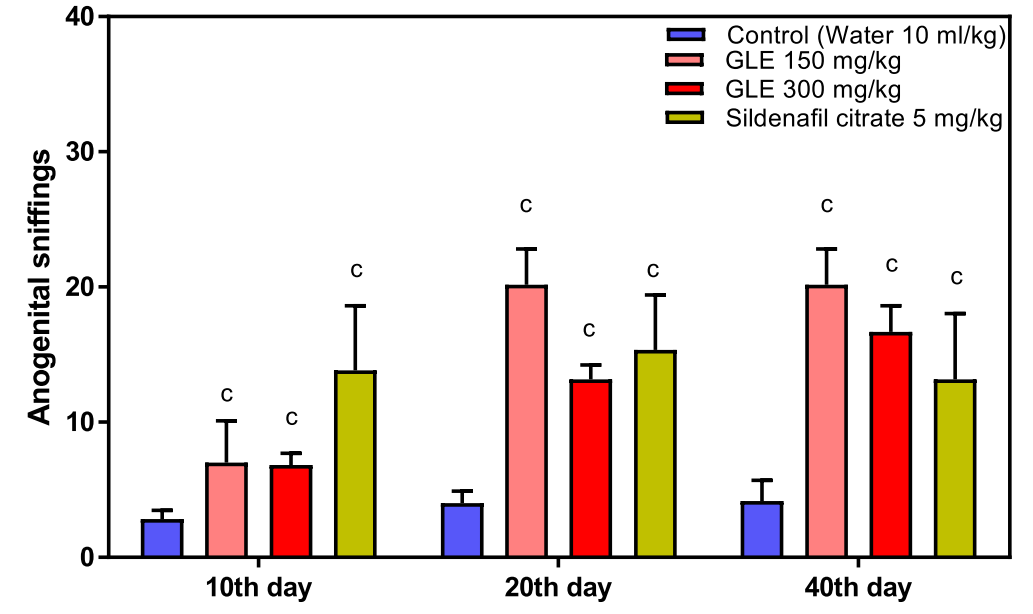

Fig. 6 Effect of Ganoderma lucidum on anogenital sniffing. Animals per group ( $\mathrm{n})=6$. The values are mean \pm S.E.M.; ${ }^{a} p<0.05 ;{ }^{b} p<0.01 ;{ }^{c} p<0.001$ when compared with control group. (One-way ANOVA followed by Tukey's post hoc test) 


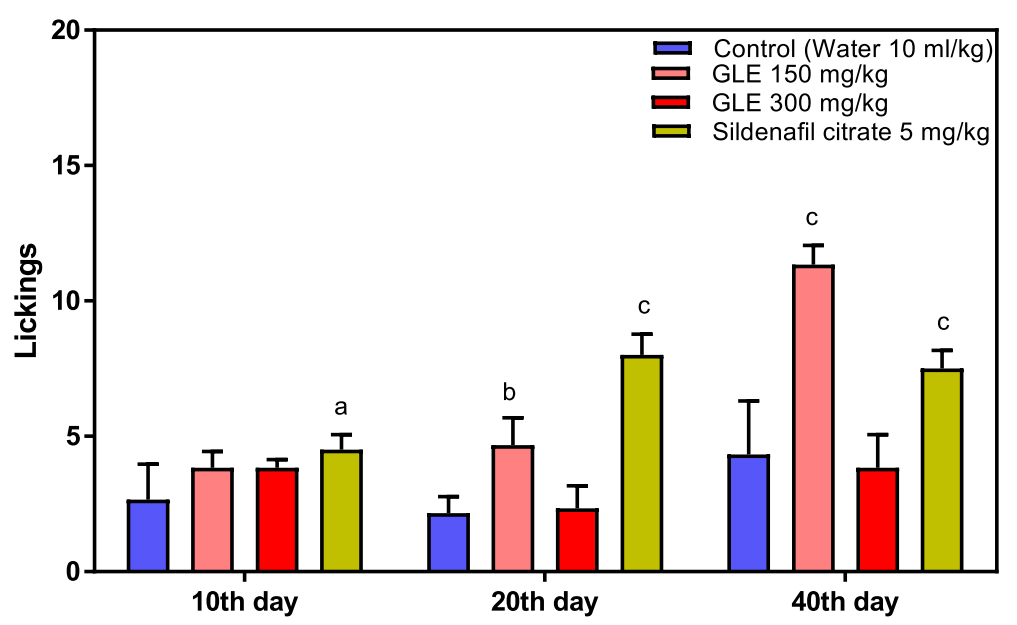

Fig. 7 Effect of Ganoderma lucidum on lickings. Animals per group $(n)=6$. The values are mean \pm S.E.M.; ${ }^{a} p<0.05 ;{ }^{b} p<0.01 ;{ }^{c} p<0.001$ when compared with control group. (One-way ANOVA followed by Tukey's post hoc test)

Moreover, there were more sperm positive females in the mating performance test which also supports the aphrodisiac potential of the extract. The similarity in the results of mating performance test of ethanol extract of Ganoderma lucidum and sildenafil citrate reveals identical aphrodisiac activity of both agents. However, in mating performance test a reverse inhibition of sexual performance was seen at the dose of $300 \mathrm{mg} / \mathrm{kg}$ of the extract on 10th and 40th day of the study which may be because of sedation in the form of negative sexual interest among the rats. The same result of sexual inhibition was shown with the findings of Afolayan and Yakubu and Ratnasooriya and Dharmasiri which supports the results of our study [24, 26].

The orientation activity of the male rat is one of the very important parameters to evaluate the aphrodisiac activity in rodents. Results of orientation activity tests of male rats showed that GLE, at the dose of $150 \mathrm{mg} / \mathrm{kg}$; significantly increased the attention of male rats towards female rats when compared with control group and sildenafil citrate $5 \mathrm{mg} / \mathrm{kg}$ group.

Many research studies have reported that increase in the sexual desire may be due to an increment in the levels of serum testosterone and anterior pituitary hormones. These hormones are considered as major stimulators of neurotransmitters such as dopamine which helps in conducting the actions related to sexual behavior and copulation [24, 27, 28]. Testosterone is an important steroidal hormone secreted from the leydig cells of the testes [29]. It has been reported that the use of testosterone significantly increases the sexual desire and function. Testosterone

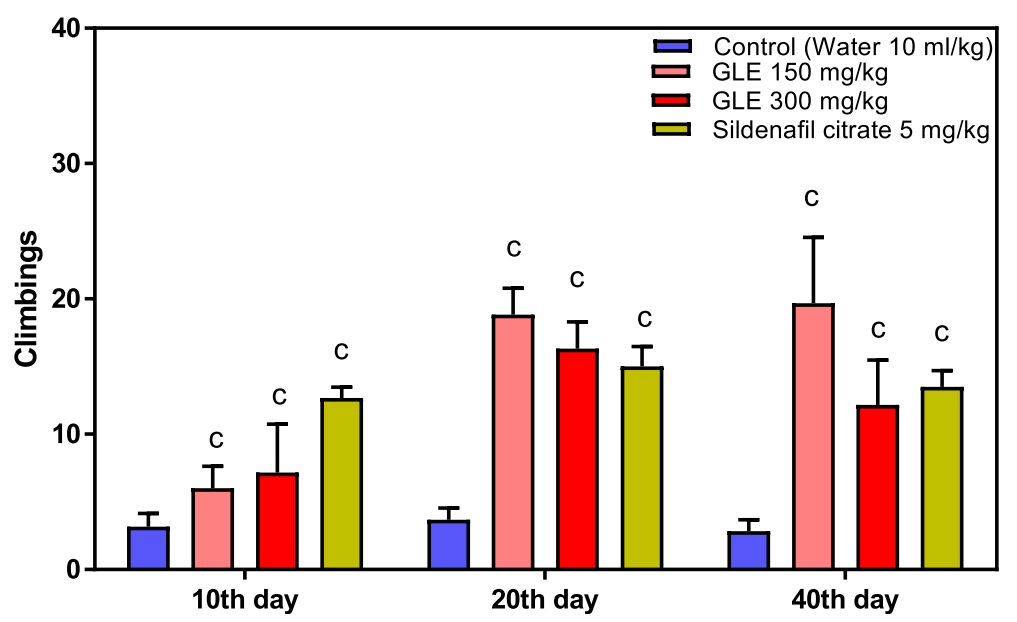

Fig. 8 Effect of Ganoderma lucidum on climbing. Animals per group $(n)=6$. The values are mean \pm S.E.M.; ${ }^{a} p<0.05 ;{ }^{b} p<0.01 ;{ }^{c} p<0.001$ when compared with control group. (One-way ANOVA followed by Tukey's post hoc test) 


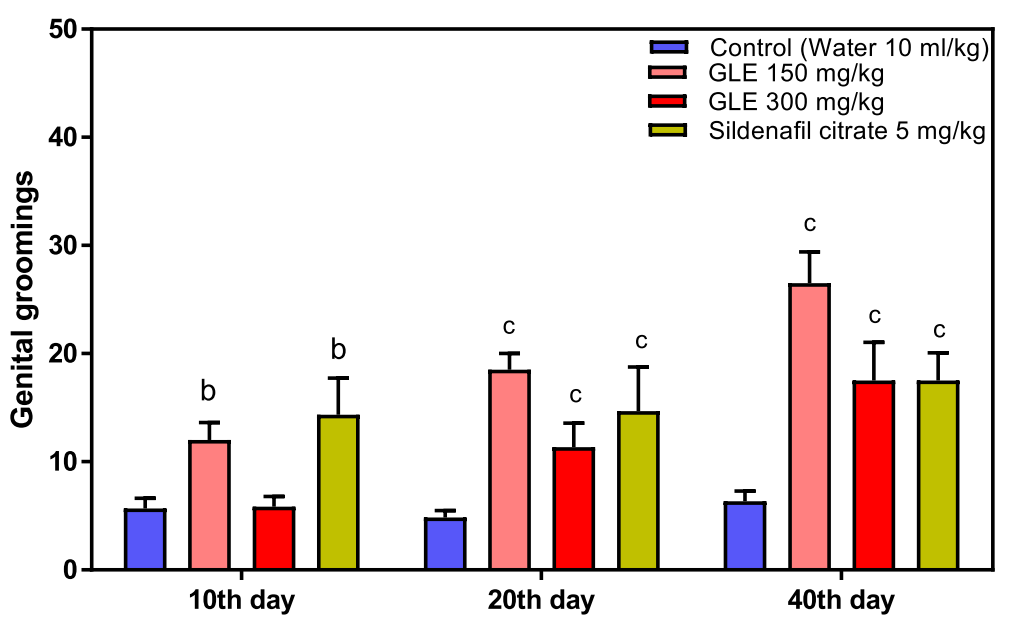

Fig. 9 Effect of Ganoderma lucidum on genital grooming. Animals per group $(n)=6$. The values are mean \pm S.E.M.; ${ }^{a} p<0.05 ;{ }^{b} p<0.01 ;{ }^{c} p<0.001$ when compared with control group. (One-way ANOVA followed by Tukey's post hoc test)

also increases the climax of sexual excitement and ejaculation [30, 31].

The results of our study show that Ganoderma lucidum significantly elevated the testosterone level in male rats. This increase in the testosterone level is the most important parameter to establish the aphrodisiac potential of the GLE.

Certain bioactive compounds play the major role in enhancing testosterone levels endogenously and for boosting the sexual behavior in males. These compounds work by special mechanism which includes: steroids by promoting androgen production $[32,33]$ alkaloids through widening the blood vessels in the reproductive organs, saponins through stimulating gonadal tissue and CNS by means of NO based mechanism [34] flavonoids by increasing testosterone synthesis or by preventing its metabolic deterioration $[35,36]$ Steroids are one of the dominant

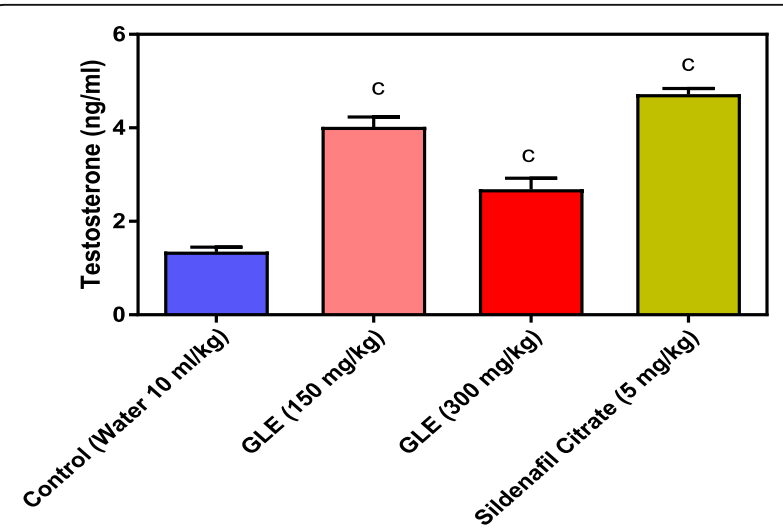

Fig. 10 Effect of Ganoderma lucidum on testosterone levels. Animals per group $(n)=6$. The values are mean \pm S.E.M.; ${ }^{a} p<0.05 ;{ }^{b} p<0.01$; ${ }^{c} p<0.001$ when compared with control group. (One-way ANOVA followed by Tukey's post hoc test) components of Ganoderma lucidum [11]. Thus, the enhancement in sexual activity exhibited in the present study may be due to the presence of steroids in GLE.

\section{Conclusion}

According to Solomon P. Wasser [37], Ganoderma lucidum was traditionally used to manage male sexual dysfunction. This study was designed to investigate and establish the traditional aphrodisiac potential of the herb. The results of this study show that the parameters of mounting behavior test, mating performance test, orientation activities and the test for libido were increased in the animals treated with GLE when compared with the animals treated with distilled water. The increase in above mentioned parameters may due to enhancing effect of GLE on the testosterone levels. Hence, we conclude that GLE may be a new promising aphrodisiac agent, which can be used to promote the sexual performance of many troubled men.

\section{Abbreviations}

ANOVA: Analysis of variance; CNS: Central nervous system; ELISA: Enzyme linked immunosorbent assay; GLE: Ganoderma lucidum extract; kg: Kilogram; MF: Mounting frequency; mg: Milligram; NO: Nitric oxide; rpm: Rotations per minute; SEM: Standard error of mean

\section{Funding}

This research study was not granted any specific fund.

\section{Authors' contributions}

Study design and supervision, analysis of data, graphical representation, interpretation of results and drafting manuscript were done by MA. Sample collection and laboratory experiments were performed by HA. Both authors read and approved the final manuscript.

\section{Ethics approval}

Handling of the animals was done according to the requirements mentioned in "Guidelines for the care and use of laboratory animals $8^{\text {th }}$ edition". Prior approval of the ethical review committee of Ziauddin University was taken before starting this research study. 


\section{Consent for publication}

Not applicable

\section{Competing interests}

The authors declare that they have no competing interests.

\section{Publisher's Note}

Springer Nature remains neutral with regard to jurisdictional claims in published maps and institutional affiliations.

Received: 27 February 2018 Accepted: 21 August 2018

Published online: 29 October 2018

\section{References}

1. Kothari P. Common sexual problems - solutions. 2nd ed. New Delhi: UBS Publishers Distributors (P), Limited; 1994

2. Kulkarni SK, Reddy DS. Pharmacotherapy of male erectile dysfunction with sildenafil. Indian J Pharmacol. 1998;30(6):367-8.

3. Aagaard L, Hansen E. Side effects reported by European consumers for medications for erectile dysfunction. J Res Pharm Pract. 2013;2(2):93.

4. Hammoud MA, Jin F, Lea T, Maher L, Grierson J, Prestage G. Off-label use of phosphodiesterase type 5 inhibitor erectile dysfunction medication to enhance sex among gay and bisexual men in Australia: results from the FLUX study. J Sex Med. 2017:14(6):774-84

5. Wasser SP, Weis AL. Therapeutic effects of substances occurring in higher Basidiomycetes mushrooms: a modern perspective. Critc Rev Immunol. 1999;19(1):1-32.

6. De Silva DD, Rapior S, Fons F, Bahkali AH, Hyde KD. Medicinal mushrooms in supportive cancer therapies: an approach to anti-cancer effects and putative mechanisms of action. Fungal Divers. 2012;55(1):1-35.

7. Babu PD, Subhasree RS. The sacred mushroom "Reishi"-a review. AmericanEuras. J Bot. 2008;1(3):107-10

8. Chang ST, Buswell JA. Ganoderma lucidum (Curt.: Fr.) P. Karst. (Aphyllophoromycetideae) - a mushrooming medicinal mushroom. Int J Med Mushrooms. 1999:1(2):139-46.

9. Shiao MS. Natural products of the medicinal fungus Ganoderma lucidum: occurrence, biological activities, and pharmacological functions. The Chem Record. 2003;3(3):172-80

10. Gordan JD, Chay WY, Kelley RK, Ko AH, Choo SP, Venook AP. And what other medications are you taking? J Clin Oncol. 2011;29(11):e288-91.

11. McKenna D, Jones K, Hughes K. Botanical Medicines. New York: Routledge; 2011

12. Gao Y, Zhou S, Chen G, Dai X, Ye J. A phase I/II study of a Ganoderma lucidum (Curt.: Fr.) P. Karst. Extract (Ganopofy) in patients with advanced cancer. Int J Med Mushrooms. 2002;4(3):1-8.

13. Zhao $\mathrm{XL}$, Campos AR. Insulin signalling in mushroom body neurons regulates feeding behaviour in Drosophila larvae. J Exp Biol. 2012; 215(15):2696-702

14. Batra P, Sharma AK, Khajuria R. Probing Lingzhi or Reishi medicinal mushroom Ganoderma lucidum (higher Basidiomycetes): a bitter mushroom with amazing health benefits. Int J Med Mushrooms. 2013;15(2):127-43.

15. Yuen JW, Gohel MD, Ng CF. Synergistic cytotoxic effects of Ganoderma lucidum and bacillus calmette guérin on premalignant urothelial HUC-PC cells and its regulation on proinflammatory cytokine secretion. Evid Based Complement Alternat Med. 2012;2012:1-9.

16. Li F, Zhang Y, Zhong Z. Antihyperglycemic effect of Ganoderma lucidum polysaccharides on streptozotocin-induced diabetic mice. Int J Mol Sci. 2011;12(9):6135-45.

17. Garber J, Barbee W, Bielitzki J, Clayton L, Donovan J, Kohn D, Lipman N, Locke P, Melcher J, Quimby F, Turner P, Wood G, Würbel H. Guidelines for care and use of laboratory animals. 8 Ed. Washington, D.C: The National Academies Press; 2011.

18. Aslam M, Sial AA. Effect of hydroalcoholic extract of Cydonia oblonga miller (quince) on sexual behaviour of Wistar rats. Adv Pharmacol Sci. 2014;2014:1-6.

19. Ahmad S, Latif A, Qasmi IA. Aphrodisiac activity of $50 \%$ ethanolic extracts of Myristica fragrans Houtt. (nutmeg) and Syzygium aromaticum (L) Merr. \& Perry. (clove) in male mice: a comparative study. BMC Complement Altern Med. 2003:3(1):1-6.

20. Zade V, Dabhadkar D, Thakare V, Pare S. Evaluation of potential aphrodisiac activity of Moringa oleifera seed in male albino rats. Int J Pharm Pharm Sci. 2013;5(4):683-9.
21. Pande M, Pathak A. Aphrodisiac activity of roots of Mimosa pudica Linn. Ethanolic extract in mice. Int J Pharm Sci Nanotechnol. 2009:2(1):477-86.

22. Yakubu MT, Akanji MA, Oladiji AT. Aphrodisiac potentials of the aqueous extract of Fadogia agrestis (Schweinf. Ex Hiern) stem in male albino rats. Asian J Androl. 2005;7(4):399-404

23. Yakubu MT, Akanji MA. Effect of aqueous extract of Massularia acuminata stem on sexual behaviour of male Wistar rats. Ev-Based Compl and Alter Med. 2011;2011:1-10.

24. Ratnasooriya WD, Dharmasiri MG. Effects of Terminalia catappa seeds on sexual behaviour and fertility of male rats. Asian J Androl. 2000;2(3):213-20.

25. Andersson KE. Mechanisms of penile erection and basis for pharmacologica treatment of erectile dysfunction. Pharmacol Rev. 2011;63(4):811-59.

26. Afolayan AJ, Yakubu MT. Effect of Bulbine natalensis baker stem extract on the functional indices and histology of the liver and kidney of male Wistar rats. J Med Food. 2009;12(4):814-20.

27. Giuliano F, Allard J. Dopamine and male sexual function. Europ Urol. 2001; 40(6):601-8.

28. Bahmanpour S, Talaei T, Vojdani Z, Panjehshahin MR, Poostpasand A, Zareei S, Ghaeminia M. Effect of Phoenix dactylifera pollen on sperm parameters and reproductive system of adult male rats. Iran J Med Sci. 2015;31(4):208-12.

29. Cao L, Leers-Sucheta S, Azhar S. Aging alters the functional expression of enzymatic and non-enzymatic anti-oxidant defense systems in testicular rat Leydig cells. J Steroid Biochem Mol Biol. 2004;88(1):61-7.

30. Aversa A, Fabbri A. New oral agents for erectile dysfunction: what is changing in our practice. Asian J Androl. 2001;3(3):175-9.

31. Morales AJ, Laughlin GA, Bützow $T$, Maheshwari $H$, Baumann G, Yen SS. Insulin, somatotropic, and luteinizing hormone axes in lean and obese women with polycystic ovary syndrome: common and distinct features. J Clin Endocrinol Metabol. 1996;81(8):2854-64.

32. Drewes $\mathrm{SE}$, George J, Khan F. Recent findings on natural products with erectile-dysfunction activity. Phytochemistry. 2003;62(7):1019-25.

33. Gauthaman K, Ganesan AP. The hormonal effects of Tribulus terrestris and its role in the management of male erectile dysfunction-an evaluation using primates, rabbit and rat. Phytomed. 2008;15(1-2):44-54

34. Murphy LL, Ginseng LEETJ. Sex behavior, and nitric oxide. Annal New York Acad Sci. 2002;962(1):372-7.

35. Ratnasooriya WD, Fernando TS. Effect of black tea brew of Camellia sinensis on sexual competence of male rats. J Ethnopharmacol. 2008;118(3):373-7.

36. Yang NY, Kaphle K, Wang PH, Jong DS, Wu LS, Lin JH. Effects of aqueous extracts of" betel quid" and its constituents on testosterone production by dispersed mouse interstitial cells. American J Chinese Med. 2004:32(5):705-15.

37. Wasser SP. Reishi or Ling Zhi (Ganoderma lucidum). Encycl Diet Suppl. 2005; $1: 603-22$

\section{Submit your manuscript to a SpringerOpen ${ }^{\circ}$ journal and benefit from:}

- Convenient online submission

- Rigorous peer review

- Open access: articles freely available online

- High visibility within the field

- Retaining the copyright to your article

Submit your next manuscript at $>$ springeropen.com 